\title{
Systematic Reviews and Meta-Analyses
}

\author{
Sistematik Derleme ve Meta-Analizi
}

$\mathrm{S}_{\mathrm{i}}^{\mathrm{i}}$ istematik derleme (SD); belli bir konuda yapilan orijinal araştırmaların çok detaylı ve geniş bir biçimde taranıp, dışlanma ve dahil edilme kriterleri kullanılarak, bulguların sentez edildiği bilimsel incelemedir. Meta-analiz (MA) ise; aynı konu üzerinde farklı araştırmacılar tarafından yapılmış olan çalışma sonuçlarının niteliksel ve niceliksel olarak uygun istatistiksel yöntemlerle birleştirilmesidir [1-4]. Literatürde bir konuyla ilgili yapılmış çok sayıda araştırmaya rastlamak mümkündür. Ayrıca bu araştırma sonuçlarının bazen birbiriyle çelişmektedir. SD ve MA' lerin temel ortaya çıkış nedeni, karmaşık ve çelişkili görünen bu durumdan anlamlı ve uygulanabilir sonuçlar çıkartmaktır. SD ve MA kanıt piramidinin en üstünde yer alır ve klinik uygulama klavuzları için çıkarımlar yapılabilir [4-7].
\end{abstract}

Ahmet Aslan ${ }^{1 *}$
SD ve MA'ler biyomedikal dergiler tarafından giderek artan sıklıkla kabul edilmekte ve basılmaktadır. Ancak bu yayınların faydalılı̆̆ını sağlamak ve yanlış yönlendirmeleri engellemek için yüksek standartlarla yürütülmesi önemlidir [4]. İyi bir derleme yazmak için geliştirilen PRİSMA bildirgesinde, bir kontrol listesi bulunmaktadır [8]. "Meta-analysis of Observational Studies in Epidemiology (MOOSE)” önerileri özellikle gözlemsel çalışmaların meta-analizleri için tasarlanmıştır [9]. Cochrane Sistematik Derlemeler Rehberi ise $S D$ ve MA yürütenler için temel bir kaynaktır [10].

SD ve MA'ler genellikle şu basamakları içerir: Araştırma konusunun tanımlanması, kapsamlı literatür taraması, çalı̧̧maların seçimi, verilerin toplanması, veri- lerin analizi ve sonuçların raporlanması. İyi kalitedeki sistematik derlemeler detaylı bir literatür araştırmasını gerektirmektedir. Birkaç veri tabanının araştırılması konuyla ilgili tüm çalışmaların taranmasını mümkün kılmaz. Kullanılan ana veri tabanları Medline, Embase ve Cochrane Kütüphanesi'dir. Bu veri tabanlarına ulaşmak için sıklıkla kullanılan portallar ise, PubMed ve Ovid'dir. En kapsamlı araştırmalar için çeşitli veri tabanları ve çeşitli portallar kullanılmalıdır [4]. Metaanalizlerin avantajları: Farklı çalışmaların sonuçları birleştirerek örneklem genişliği ve İstatistik gücü artt1rır, Havuzlanan özet sonuç tüm çalışmaların sonuçlarının ağırlıklı ortalamasını verir, genelleştirmeye olanak tanır. Dezavantajları ise: Sonuçlar kimi zaman yanlış yönlendirebilir, Çalışmaların tanımlanması ve değerlendirilmesi basamağı hataya açıktır, Yayın hatasından etkilenir [2-4,7].

Birçok SD ve MA, İngilizce dışındaki dillerde yayınlanan çalışmaları içermez. Bunların dahil edilmesi kesinliği artırır ve sistematik hataları azaltabilir [11]. Ayrıca tezler, komite bildirgeleri, hükümet raporları, konferans bildirileri, devam eden akademik araştırmalar, İngilizce olmayan raporlar gibi belgeleri içeren ve gri literatür olarak adlandırılan kanıtlar sistematik bir incelemeye önemli katkılarda bulunabilir $[12,13]$. İngilizce olmayan raporların, yayınlanmamış çalışmaların ve tezlerin; meta-analizlerin sonuçları üzerindeki etkileri konusunda sınırlı kanıt vardır. Bu çalışma türlerinin dahil edilmesi, özellikle konuyla ilgili az sayıda

*Sorumlu Yazar: Ahmet Aslan, Alanya Alaaddin Keykubat Üniversitesi, Tıp Fakültesi, Ortopedi ve Travmatoloji AD, Alanya, Türkiye.

Tel: +905056462411 Fax: +90 24251061 39, e-mail: ahmet.aslan@alanya.edu.tr 
çalışmanın olduğu veya yayınlanan literatürde şüpheli sonuçların olduğu durumlarda etkili olabilir [14].

Ülkemiz kaynaklı, Türkçe ya da İngilizce yazılmış, çeşitli SD ve MA rastlamak mümkündür [15-17]. Ancak sayıları yetersizdir. Diğer yandan Ülkemizde yapılan sistematik derlemelerle ilgili bir değerlendirmede önemli metodolojik problemlerinin bulunduğunu ve sistematik derleme yazımı konusunda daha fazla bilgi ve deneyime gereksinimimizin olduğu belirtilmiştir [18].

Sonuç olarak; Kanıt seviyesinin en üst basamaklarında yer alan ve günümüzde artan sıklıkta yayımlanan $\mathrm{SD}$ ve MA konusunda Ülkemizde daha sık makaleler yazılmalı ve Türkçe literatürün bilime katkısı artırılmalıdır. Acta Medica Alanya dergisi SD ve MA yayımlamayı desteklemektedir.

\section{KAYNAKLAR}

1. Gülpınar Ö, Güçlü AG. Derleme makalesi nasıl yazılır? Turkish Journal of Urology, 2013;39(Özel Sayı 1): 44-8.

2. Balıı S, Baydemir C. Sağlık Bilimlerinde Meta Analizi . Kocaeli Üniversitesi Sağlık Bilimleri Dergisi 2015;1(1):9-11.

3. Ata B, Urman B. Sistematik Derlemelerin Kritik Analizi. TJOD Derg, 2008;5(4):233-40.

4. Bown MJ, Sutton AJ. Quality control in systematic reviews and meta-analyses. Eur J Vasc Endovasc Surg. 2010 Nov;40(5):669-77.

5. Aslan A. [Evidence Based Medicine and Clinical Practise Guidlines]. Acta Med. Alanya 2018;1(1):1-2. Turkish. DOI: 10.30565/medalanya.405333

6. Akgöz S, Ercan İ, Kan İ. Meta-analizi. Uludağ Üniversitesi Tıp Fakültesi Dergis 2004;30(2):107-112

7. Blettner M, Sauerbrei W, Schlehofer B, Scheuchenpflug T, Friedenreich C. Traditional Reviews, Meta analysis and pooled analysis in epidemiology. Int J Epidemiol. 1999; 28: 1 - 9 .

8. Moher D, Liberati A, Tetzlaff J, Altman DG, Group P. Preferred reporting items for systematic reviews and meta-analyses: the PRISMA statement. J Clin Epid 2009;62(10):1006-12.

9. Stroup DF, Berlin JA, Morton SC, Olkin I, Williamson GD, Rennie D, et al. Meta-analysis of observational studies in epidemiology: a proposal for reporting. Meta-analysis Of Observational Studies in Epidemiology (MOOSE) group. JAMA 2000;283(15):2008-12.

10. Higgins JP, Green S. Cochrane handbook for systematic reviews of interventions version 5.0.2. The Cochrane Collaboration; 2009 [updated September 2009].

11. Moher D, Fortin P, Jadad AR, Juni P, Klassen T, Le Lorier J, et al. Completeness of reporting of trials published in languages other than English: implications for conduct and reporting of systematic reviews. Lancet 1996;347(8998):363-6

12. Alberani V, Pietrangeli PDC, Mazza AMR (1990). The use of grey literature in health sciences: a preliminary survey. Bulletin of the Medical Library Association 78(4): 358-363.

13. Paez A. Gray literature: An important resource in systematic reviews. J Evid Based Med. 2017 Aug;10(3):233-240.

14. Hartling L, Featherstone R, Nuspl $M$ et al. Grey literature in systematic reviews: a cross-sectional study of the contribution of non-English reports, unpublished studies and dissertations to the results of meta-analyses in child-relevant reviews. BMC Med Res Methodol. 2017 Apr 19:17(1):64.

15. Özcan NK, Bilgin H. Türkiye'de Sağlık Çalışanlarına Yönelik Şiddet: Sistematik Derleme. Türkiye Klinikleri J Med Sci 2011;31(6):1442-56

16. Ay F. Treatment of postoperative pain and non-pharmacologic practices in nursing systematic review: Results of Turkish doctoral dissertation in 2000-2015. Agri 2018;30(2):71-83

17. Aykan ŞB, Çiftci IH. Meta-Analiz: Türkiye'de Pseudomonas aeruginosa Izolatlarının Son 11 Yıldaki Antibiyotik Direnç Değişimi. Mikrobiyol Bul 2015; 49(3): 352-365

18. Karaçam Z. Sistematik Derleme Metodolojisi: Sistematik Derleme Hazırlamak İçin Bir Rehber. DEUHYO ED 2013,6 (1), 26-33.
Geliş Tarihi:01.07.2018 / Kabul Tarihi:02.07.2018 / Yayınlanma Tarihi:02.07.2018

How to cite this article/Bu makaleye atıf için: Ahmet A. Systematic Reviews and Meta-Analyses Acta Med. Alanya 2018;2(2):62-63 [Turkish] DOI: $10.30565 /$ medalanya.439541 